\title{
COMUNICAÇÃo
}

\section{HATCHING OF EGGS OF DIPETALOGASTER MAXIMUS KEPT UNDER DIFFERENT CLIMATIC CONDITIONS}

\author{
M. T. García-Zapata, M. Vidal and P. D. Marsden
}

The use of Dipetalogaster maximus in xenodiagnosis has been reviewed ${ }^{2}$. We continue to investigate relevant biological aspects of this species. We report here the results of exposing newly laid eggs to more controlled temperature (mean $28^{\circ} \mathrm{C}$, range $\left.27-30^{\circ} \mathrm{C}\right)$ and humidity $(50 \%$ mean, range 47-50) and to Brasilia enviromental conditions (temperature $22^{\circ} \mathrm{C}$, range $10-34$; humidity $40 \%$, range 10-90). Experiences were duplicated using
40 eggs in each batch.

The results shown in the Figure 1 confirm previous observations ${ }^{1}$. Egg lots maintained in ambient conditions hatched in a mean of 36 days (range 21-47). Those in the more controlled conditions of our insect colony hatcher earlier (mean 23 days, range 12-27). The results confirm the value of keeping the colony under controlled ambiental conditions.

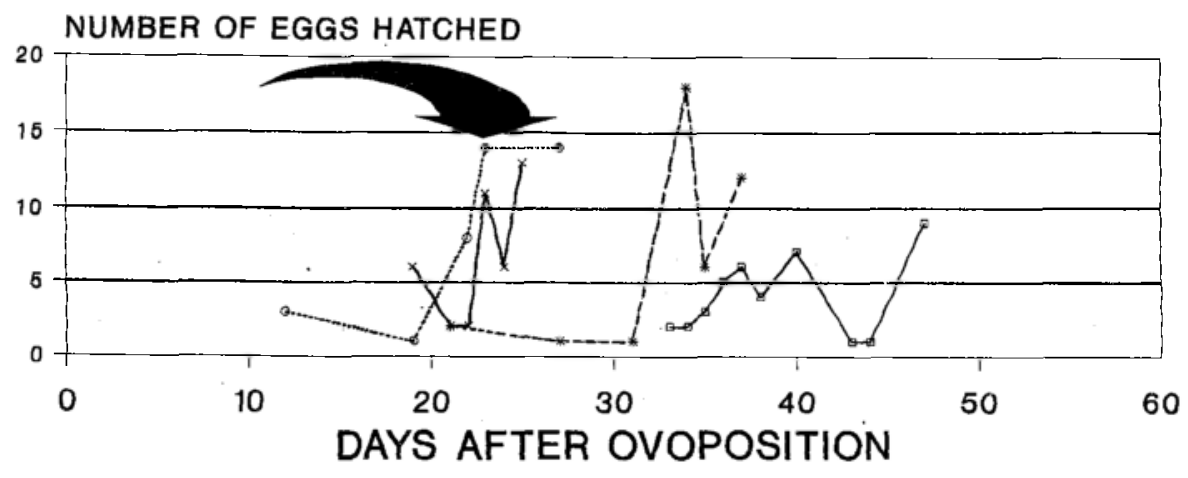

Figure 1-EGG hatching of the four batches of 40 eggs of Dipetalogaster maximus. (NMTN-UnB, 05/10/92 - 16/03/93).

\section{REFERENCES}

1. Barreto AC, Prata AR, Marsden PD, Cuba CC, Trigueiro CP. Aspectos biológicos e criação em massa de Dipetalogaster maximus (Ulher, 1894) (Triatominae). Revista do Instituto de Medicina
Tropical de São Paulo 23:18-27, 1981.

2. Marsden PD. Dipetalogaster maxima or maximus as a xenodiagnostic agent. Revista da Sociedade Brasileira de Medicina Tropical 19:205-207, 1986. 